\title{
PENGARUH KOMPENSASI DAN LINGKUNGAN KERJA TERHADAP KEPUASAN KERJA PT. AUTO PRIMA JAYA
}

\author{
Fillipo $^{1}$, Yusi Yusianto ${ }^{2}$, Sanny Ekawati ${ }^{3}$ \\ ${ }^{1}$ Program Studi Manajemen, Fakultas Ekonomi dan Bisnis, Universitas Tarumanagara \\ Email: fillipo.115170105@stu.untar.ac.id \\ ${ }^{2}$ Program Studi Manajemen, Fakultas Ekonomi dan Bisnis, Universitas Tarumanagara* \\ Email: yusiy@fe.untar.ac.id \\ ${ }^{3}$ Program Studi Manajemen, Fakultas Ekonomi dan Bisnis, Universitas Tarumanagara \\ Email: sannye@fe.untar.ac.id \\ *Penulis Korespondensi
}

\begin{abstract}
ABSTRAK
Penelitian ini bertujuan untuk mengetahui pengaruh kompensasi dan lingkungan kerja terhadap kepuasan kerja karyawan PT. Auto Prima Jaya. Jumlah sampel yang digunakan dalam penelitian sebanyak 69 responden. Desain penelitian yang digunakan adalah kausal dengan menggunakan metode kuantitatif dan kuesioner dalam bentuk google form. Penelitian ini menggunakan smartPLS dalam mengolah data. Hasil penelitian dapat disimpulkan bahwa kompensasi dan lingkungan kerja memiliki pengaruh yang positif dan signifikan terhadap kepuasan kerja karyawan di PT. Auto Prima Jaya.
\end{abstract}

Kata Kunci: Kompensasi, Lingkungan Kerja, Kepuasan Kerja

\section{ABSTRACT}

The aim of this research was to determine the effect of compensation and work environment on employee job satisfaction at PT. Auto Prima Jaya. The number of samples used in the study was 69 respondents. The research design used was causal using quantitative methods and questionnaires in google form. The collected data was analyzed using smartPLS. The results of the study concluded that compensation and work environment have a positive effect and significant on employee job satisfaction at PT. Auto Prima Jaya.

Keywords: Compensation, Work Environment, Job Satisfaction

\section{PENDAHULUAN}

\section{Latar Belakang}

Sumber daya manusia merupakan salah satu aset penting yang dimiliki oleh perusahaan. Mengelola sumber daya manusia dengan baik merupakan kunci agar perusahaan memiliki tenaga kerja yang diharapkan memberikan kinerja yang maksimal. Perusahaan perlu memahami peran dari setiap karyawannya agar tugas yang dikerjakan menjadi efektif dan efisien serta tujuan perusahaan dapat dicapai.

Perusahaan dapat mempertahankan karyawannya, dengan cara memahami kepuasan kerja karyawannya, apakah mereka merasa puas dengan pekerjaan yang dilakukannya atau tidak. Kepuasan kerja merupakan perasaan positif yang dihasilkan dari persepsi bahwa pekerjaan seseorang dapat memenuhi nilai-nilai penting dari pekerjaannya (Noe dkk, 2010). Jika karyawan merasa puas dengan pekerjaannya maka diharapkan karyawan akan memberi kontribusi yang terbaik pada perusahaan. (Landy dan Conte, 2013), memberi gambaran mengenai sejarah penelitian kepuasan kerja dan memberi kesimpulan bahwa terdapat dua sumber yang 
memengaruhi kepuasan kerja, yakni peristiwa atau kondisi dan agen. Peristiwa atau kondisi terdiri dari, antara lain, tantangan, kebutuhan fisik serta minat atas pekerjaannya; imbalan; dan kondisi fisik serta pencapaian tujuan. Agen terdiri dari, antara lain, karyawan yang bersangkutan; atasan, rekan kerja dan bawahan; perusahaan dan manajemen; dan tunjangan.

Kompensasi merupakan salah satu faktor yang mempengaruhi kepuasan kerja. Kompensasi adalah semua bentuk pembayaran yang diberikan kepada karyawan atas hasil kerja mereka (Dessler, 2017). Pemberian kompensasi yang adil sesuai dengan pekerjaan, dapat memotivasi dan meningkatkan kepuasan kerja. Kompensasi juga merupakan alasan penting yang mempengaruhi karyawan untuk bekerja pada suatu perusahaan dan tidak pada perusahaan lain.

Faktor lain yang berperan penting untuk mempengaruhi kepuasan kerja adalah lingkungan kerja. Karyawan akan sulit untuk memberikan kontribusi yang baik jika lingkungan kerja tidak mendukung aktivitasnya. Perusahaan dapat mendukung karyawan dalam memberikan kontribusi yang baik, dengan menyiapkan program pelatihan yang sesuai dengan kebutuhan pekerjannya. Dalam pelatihan yang diberikan tidak hanya fokus pada kemampuan atas pekerjaan, tetapi diharapkan pola pikir dan cara pandang juga terbentuk terhadap lingkungan kerja yang ada. Dengan menciptakan lingkungan kerja yang baik, nyaman dan mendukung pekerjaan dapat membantu karyawan untuk mencapai hasil yang optimal, sehingga penting bagi perusahaan untuk selalu memperhatikan lingkungan kerja sekitar (Sedarmayanti, 2009).

Tujuan penelitian ini adalah untuk mengetahui :

a. Untuk mengetahui bagaimana pengaruh kompensasi terhadap kepuasan kerja karyawan pada PT. Auto Prima Jaya.

b. Untuk mengetahui bagaimana pengaruh lingkungan kerja terhadap kepuasan kerja karyawan pada PT. Auto Prima Jaya.

\section{Kajian teori \\ Kepuasan Kerja}

Kepuasan kerja merupakan tanggapan sikap dan emosional karyawan terhadap pekerjaan yang mereka lakukan (Robbins, DeCenzo dan Coulter, 2013; Kreitner dan Kinicki, 2014). Kepuasan kerja disebabkan oleh beberapa faktor, antara lain, pekerjaan itu sendiri, penghargaan yang adil, supervisi, dan rekan kerja (Robbins, Judge, dan Breward, 2016). Kepuasan kerja karyawan memiliki lima model utama, antara lain, pemenuhan kebutuhan karyawan, pemenuhan harapan karyawan, pencapaian nilai, persepsi karyawan mengenai keadilan di tempat kerja, dan komponen karakter pekerja (Kinicki dan Fugate, 2018).

\section{Kompensasi}

Kompensasi merupakan seluruh imbalan dalam bentuk uang dan barang langsung atau tidak langsung yang diterima oleh karyawan sebagai imbalan atas jasanya pada perusahaan (Mondy dan Martocchio, 2016; Hasibuan, 2012). Kompensasi memiliki dua komponen, yaitu kompensasi finansial dan non-finansial (Mondy dan Martocchio, 2016). Kompensasi finansial dibedakan menjadi dua, yaitu langsung dan tidak langsung. Kompensasi finansial langsung berupa gaji, upah, insentif, dan bonus dan kompensasi finansial tidak langsung mencakup berbagai macam penghargaan yang biasanya diterima secara tidak langsung oleh karyawan seperti liburan berbayar dan perawatan medis. Kompensasi non-finansial terdiri dari kepuasan yang diterima seseorang dari pekerjaan itu sendiri, yang ditekankan pada pembentukan kondisi kerja yang baik. 
Sistem pembayaran kompensasi dirancang untuk mencapai tujuan tertentu. Tujuan dasar pembayaran kompensasi, mencakup, antara lain, efisiensi, adil, etis dan sesuai dengan hukum dan peraturan (Milkovich, Newman dan Gerhart, 2011). Tujuan efisiensi berkaitan dengan sistem pembayaran yang dapat mendorong untuk memperbaiki kinerja dan mengendalikan biaya tenaga kerja. Tujuan adil berkaitan dengan sistem pembayaran yang memberi perlakuan adil kepada seluruh karyawannya. tujuan etis berkaitan dengan sistem pembayaran yang juga mempertimbangkan cara atau bagaimana pendapatan perusahaan diperoleh sehingga terhindar dari pelanggaran etika. Tujuan yang sesuai dengan hukum dan peraturan adalah sistem pembayaran yang sesuai dengan hukum dan peraturan di wilayah mana perusahaan berada.

\section{Lingkungan Kerja}

Lingkungan kerja merupakan segala sesuatu yang berada di sekitar karyawan dan dapat berpengaruh dalam proses kerjanya (Al-Omari dan Okasheh, 2017). Lingkungan kerja merupakan tempat dimana karyawan melakukan aktivitasnya, yang dapat mempengaruhi baik secara positif maupun negatif bagi karyawan untuk mencapai tujuan kerjanya (Pawirosumarto, Sarjana dan Gunawan, 2016). Faktor yang mempengaruhi lingkungan kerja, antara lain, dukungan oleh rekan kerja, dukungan oleh atasan, dukungan tekonolgi, dukungan anggaran, peluang untuk tampil, lingkungan fisik dan estetika, dan beban kerja (Zhang, 2015).

Berdasarkan uraian diatas, dapat disimpulkan kerangka pemikiran pada penelitian seperti pada gambar dibawah ini:

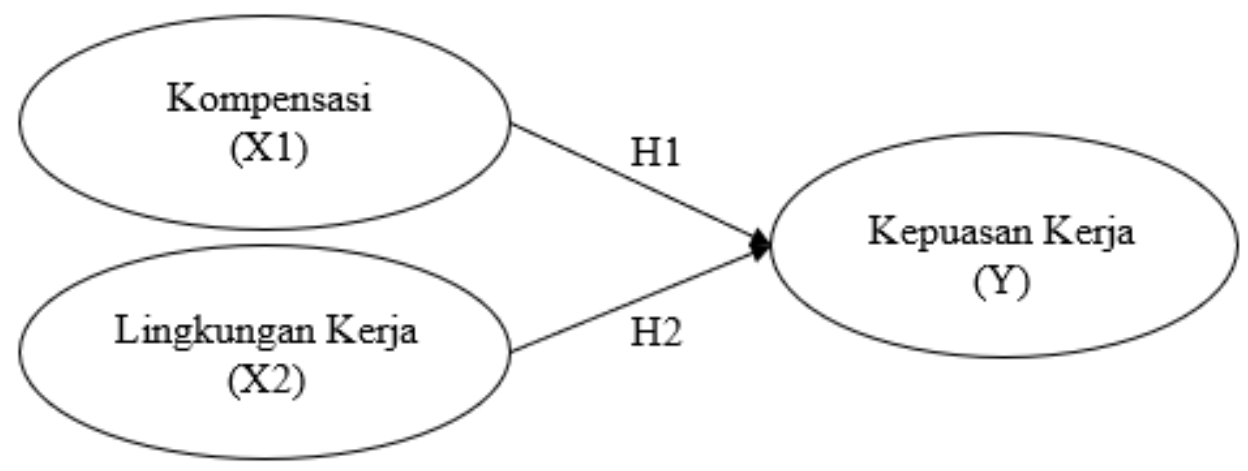

Gambar 1. Kerangka pemikiran

Berdasarkan kajian teori dan kerangka pemikiran, maka hipotesis yang dipakai dalam penelitian ini adalah sebagai berikut:

H1: Kompensasi berpengaruh positif dan signifikan terhadap kepuasan kerja karyawan.

H2: Lingkungan Kerja berpengaruh positif dan signifikan terhadap kepuasan kerja karyawan.

\section{METODE PENELITIAN}

\section{Desain Penelitian}

Desain penelitian yang digunakan pada penelitian ini adalah studi kausal. Studi kausal merupakan suatu penelitian untuk menguji hubungan sebab akibat antar variable (Sekaran dan Bougie, 2016). Melalui penelitian ini akan diuji apakah perubahan satu variabel mempengaruhi perubahan variabel lainnya.

\section{Populasi}

Pada penelitian ini populasinya adalah karyawan PT. Auto Prima Jaya yang berjumlah 73 orang. 


\section{Teknik Pemilihan Sampel}

Pada penelitian ini, metode pemilihan sampel yang digunakan yaitu purposive sampling. Purposive sampling merupakan jenis pengambilan sampel yang terbatas pada jenis orang tertentu yang dapat memberikan informasi yang diinginkan, baik karena hanya mereka yang memilikinya atau sesuai dengan kriteria yang telah ditetapkan (Sekaran dan Bougie, 2016). Kriteria sampel dalam penelitian ini, antara lain, karyawan tetap yang minimal telah bekerja selama satu tahun dengan pendidikan terakhir minimal SMA. Pengambilan sample yang dibutuhkan menggunakan google form.

\section{Ukuran Sampel}

Ukuran sampel yang layak yaitu berjumlah tidak kurang dari 30 dan tidak lebih dari 500 (Sekaran dan Bougie, 2016). Jumlah sampel yang diambil untuk penelitian ini adalah 69 responden.

\section{Operasionalisasi Variabel}

Operasional variabel penelitian ini dapat dilihat pada tabel berikut ini:

Tabel 1. Operasional Variabel Kepuasan Kerja

\begin{tabular}{|c|l|c|c|}
\hline Variabel & \multicolumn{1}{|c|}{ Pernyataan } & Kode & Sumber \\
\hline \multirow{5}{*}{ Kepuasan Kerja } & 1. Bangga dengan pekerjaan. & KK1 & Bailey, \\
\cline { 2 - 4 } & 2. Puas dengan gaji yang diterima. & KK2 & Albassami, \\
Al-Meshal, \\
\cline { 2 - 4 } & 3. Peraturan di tempat kerja cukup adil/fair. & KK3 & (2016) \\
\cline { 2 - 4 } & 4. Karyawan memiliki kesempatan untuk mengembangkan karir. & KK4 & KK5 \\
\cline { 2 - 4 } & 5. Atasan baik pada karyawan. & KK6 \\
\cline { 2 - 4 } & 6. Memiliki hubungan yang baik dengan rekan kerja. & KK7 \\
\cline { 2 - 4 } & 7. Nyaman dengan lingkungan kerja. & \\
\hline
\end{tabular}

Tabel 1. Operasional Variabel Lingkungan Kerja

\begin{tabular}{|c|l|c|c|}
\hline Variabel & \multicolumn{1}{|c|}{ Pernyataan } & Kode & Sumber \\
\hline \multirow{5}{*}{$\begin{array}{c}\text { Lingkungan } \\
\text { Kerja }\end{array}$} & 1. Rekan kerja menunjang kelancaran pekerjaan. & LK1 & Zhang \\
\cline { 2 - 4 } & 2. Perusahaan memiliki program pelatihan untuk karyawan. & LK2 \\
\cline { 2 - 4 } & 3. Perusahaan mempunyai aturan yang jelas. & LK3 \\
\cline { 2 - 5 } & $\begin{array}{l}\text { 4. Atasan mendorong karir karyawan. } \\
\text { 5erusahaan menciptakan iklim yang menunjang produktivitas } \\
\text { karyawan. }\end{array}$ & LK5 \\
\cline { 2 - 4 } & 6. Perusahaan menyediakan fasilitas yang menunjang pekerjaan. & LK6 \\
\hline
\end{tabular}

Tabel 3. Operasional Variabel Kompensasi

\begin{tabular}{|c|l|c|c|}
\hline Variabel & \multicolumn{1}{|c|}{ Pernyataan } & Kode & Sumber \\
\hline \multirow{5}{*}{ Kompensasi } & 1. Gaji yang diterima dapat memenuhi kesejahteraan. & K1 & Sedarmayanti \\
\cline { 2 - 3 } & 2. Gaji dibayar tepat waktu. & K2 & \multirow{2}{*}{ (2016) } \\
\cline { 2 - 4 } & 3. Perusahaan memberikan bonus tahunan jika target divisi tercapai. & K3 \\
\cline { 2 - 4 } & 4. Insentif diberikan pada karyawan yang berprestasi. & K4 \\
\cline { 2 - 4 } & 5. Perusahaan memberikan fasilitas asuransi. & K5 & K6 \\
\cline { 2 - 4 } & 6. Gaji lebih baik dari perusahaan lain yang sejenis. & \multicolumn{2}{|c}{} \\
\hline
\end{tabular}

\section{HASIL DAN PEMBAHASAN \\ Deskripsi Subyek Penelitian}

Dalam deskripsi subjek penelitian ini, akan diuraikan lebih lanjut mengenai responden yang dominan dan dijabarkan mulai jenis kelamin, usia, pendidikan terakhir, lama bekerja, dan divisi. Karakteristik responden akan disajikan dalam tabel sebagai berikut: 
Tabel 4. Deskripsi Subjek Penelitian

\begin{tabular}{|c|c|c|}
\hline Karakteristik Responden & Jumlah Responden Terbanyak & Presentase \\
\hline Jenis Kelamin & Laki-laki (35 orang) & $50,7 \%$ \\
\hline Usia & $20-30$ tahun (42 orang) & $60,9 \%$ \\
\hline Pendidikan Terakhir & SMA/SMK (28 orang) & $40,6 \%$ \\
\hline Lama Bekerja & $3-4$ tahun (25 orang) & $36,2 \%$ \\
\hline Divisi & Penjualan (18 orang) & $26,1 \%$ \\
\hline
\end{tabular}

Berdasarkan pada Tabel 4, diketahui dari 69 responden, jenis kelamin yang dominan yaitu responden laki-laki sebanyak 35 orang (50.7\%). Usia yang dominan dari responden yaitu 20-30 tahun sebanyak 42 orang $(60.9 \%)$. Pendidikan terakhir yang dominan dari responden yaitu SMA/SMK sebanyak 28 orang (40.6\%). Waktu lama bekerja yang dominan dari responden yaitu 3-4 tahun sebanyak 25 orang (36.2\%). Divisi yang dominan dari responden yaitu divisi penjualan sebanyak 18 orang $(26.1 \%)$.

\section{Hasil Analisis Data}

Tabel 5. Hasil Uji Convergent Validity

\begin{tabular}{|c|c|c|c|c|c|}
\hline \multicolumn{2}{|c|}{ Kepuasan Kerja } & \multicolumn{2}{c|}{ Kompensasi } & \multicolumn{2}{c|}{ Lingkungan Kerja } \\
\hline KK1 & 0.820 & K4 & 0.760 & LK1 & 0.824 \\
\hline KK2 & 0.725 & K5 & 0.770 & LK2 & 0.824 \\
\hline KK3 & 0.773 & K6 & 0.764 & LK6 & 0.777 \\
\hline KK7 & 0.725 & & & & \\
\hline
\end{tabular}

Berdasarkan hasil nilai loading factors pada Tabel 5. Setiap indikator pada masing-masing variable penelitian ini dikatakan valid, karena memiliki nilai loading factor lebih dari 0.7.

Tabel 6. Hasil Uji Composite Reliability, Average Variance Extracted, dan Cronbach Alpha

\begin{tabular}{|c|c|c|c|}
\hline Variabel & Composite Reliability & $\begin{array}{c}\text { Average Variance } \\
\text { Extracted }\end{array}$ & Cronbach's Alpha \\
\hline Kompensasi & 0,809 & 0,585 & 0,648 \\
\hline Lingkungan Kerja & 0,850 & 0,654 & 0,736 \\
\hline Kepuasan Kerja & 0,846 & 0,580 & 0,759 \\
\hline
\end{tabular}

Berdasarkan pada Tabel 6. Composite reliability dinyatakan reliable karena memiliki nilai yang lebih besar dari 0,7. Average variance extracted dinyatakan valid karena nilai pada setiap variable sudah lebih dari 0,5. Cronbach alpha dinyatakan reliable karena nilai yang diperlukan yaitu lebih dari 0,6.

\section{Uji Koefisien Determinasi $\left(\mathbf{R}^{2}\right)$}

Tabel 7. Hasil Uji Koefisien Determinasi (R2)

\begin{tabular}{|c|c|}
\hline Variabel & R-Square \\
\hline Kepuasan Kerja & 0.623 \\
\hline
\end{tabular}

Berdasarkan pada tabel 7. Hasil $R$-Square pada penelitian ini yaitu 0.623 , yang berarti $62.3 \%$ variabel kepuasan kerja dapat dijelaskan oleh variabel kompensasi dan lingkungan kerja. Sisanya sebesar $37.7 \%$, dapat dijelaskan variabel lain yang tidak diteliti pada penelitian ini. 


\section{Uji Predictive Relevance $\left(\mathrm{Q}^{2}\right)$}

Tabel 8. Hasil Uji Predictive Relevance $\left(\mathrm{Q}^{2}\right)$

\begin{tabular}{|c|c|}
\hline Variabel & $\mathbf{Q}^{2}$ \\
\hline Kepuasan Kerja & 0.329 \\
\hline
\end{tabular}

Berdasarkan pada Tabel 8. Hasil Predictive Relevance pada penelitian ini menjelaskan bahwa hubungan konstruk variabel-variabel yang diteliti dalam penelitian ini dianggap relevan untuk mengukur model penelitian yang telah terbentuk sebelumnya dengan baik, karena memiliki nilai $\mathrm{Q}^{2}$ lebih besar dari 0 .

\section{Uji Kecocokan Model (Goodness of Fit)}

GOF digunakan untuk membuktikan performa gabungan antara model pengukuran dan model struktural secara keseluruhan. Berikut merupakan hasil dari GOF:

Nilai $\overline{A V E}=(0.580+0.585+0.654): 3=0.606$

Nilai $\overline{R^{2}}=0.623$

$$
\begin{aligned}
& \text { GOF }=\sqrt{\overline{A V E} x \overline{R^{2}}} \\
& \text { GOF }=\sqrt{0.606 \times 0.623} \\
& \text { GOF }=0.6144412096
\end{aligned}
$$

Dapat disimpulkan dari perhitungan di atas bahwa Goodnes of Fit memiliki nilai yang besar yaitu 0.6144412096, karena hasilnya lebih besar dari 0.36 .

\section{Uji Hipotesis (Path Coefficient)}

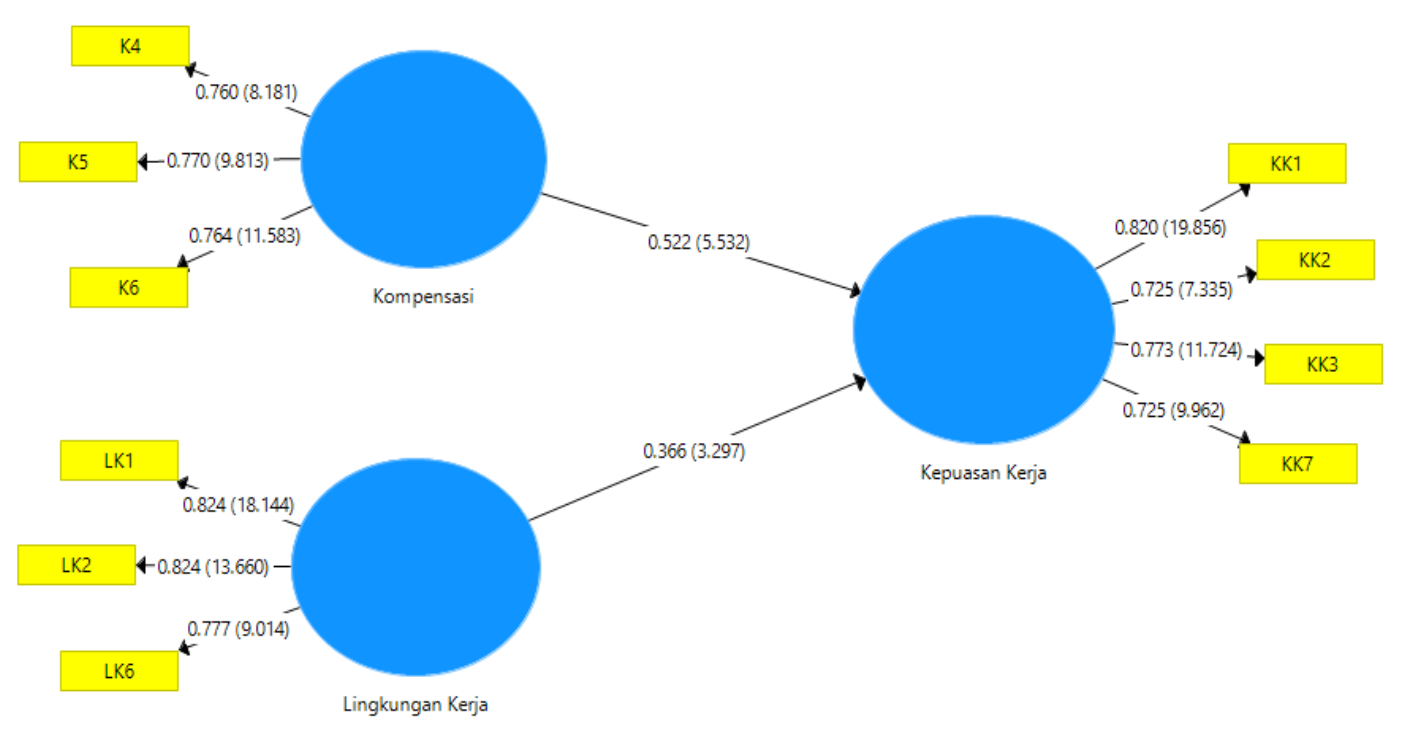

Gambar 2. Hasil Uji Path Coefficient dan t-test 
Tabel 9. Hasil Uji Path Coefficient dan t-test

\begin{tabular}{|c|c|c|c|}
\hline Variabel & Path Coefficient & t-statistics & p-value \\
\hline Kompensasi - Kepuasan Kerja & 0.522 & 5.532 & 0.000 \\
\hline Lingkungan Kerja - Kepuasan Kerja & 0.366 & 3.297 & 0.001 \\
\hline
\end{tabular}

Berdasarkan pada Tabel 9. Varibel kompensasi dikatakan memiliki pengaruh positif terhadap variabel kepuasan kerja karena nilai path coefficient yang diperoleh sebesar 0.522 , dan nilai $T$ statistics yang diperoleh sebesar $5.532(>1.96)$ serta nilai $p$-value sebesar $0.000(<0.05)$ yang artinya berpengaruh signifikan. Variabel lingkungan kerja juga memiliki pengaruh positif terhadap variabel kepuasan kerja karena nilai path coefficient yang diperoleh sebesar 0.366, dan nilai $T$-statistics yang diperoleh sebesar 3.297 (>1.96) serta nilai $p$-value sebesar $0.001(<0.05)$ yang artinya berpengaruh signifikan.

Dari hasil pengujian hipotesis, dapat disimpulkan bahwa:

H1: Kompensasi berpengaruh positif dan signifikan terhadap kepuasan kerja karyawan. Berdasarkan dari hasil pengujian hipotesis variable kompensasi (X1), nilai path coefficient sebesar 0.522 dengan nilai $T$-statistics sebesar 5.532 dan nilai $P$-value sebesar 0.000. Dapat dikatakan kompensasi (X1) memiliki pengaruh positif dan signifikan terhadap kepuasan kerja (Y).

\section{H2: Lingkungan Kerja berpengaruh positif dan signifikan terhadap kepuasan kerja karyawan.}

Berdasarkan dari hasil pengujian hipotesis variable lingkungan kerja (X2), nilai path coefficient sebesar 0.366 dengan nilai T-statistics sebesar 3.297 dan nilai $P$-value sebesar 0.001. Dapat dikatakan lingkungan kerja (X2) memiliki pengaruh positif dan signifikan terhadap kepuasan kerja (Y).

\section{Diskusi}

Penelitian ini dilakukan pada karyawan PT. Auto Prima Jaya dengan jumlah 69 responden. Dari 69 responden tersebut, jenis kelamin yang lebih dominan yaitu laki-laki berjumlah 35 responden (50.7\%), usia yang dominan yaitu diantara 20-30 tahun berjumlah 42 responden (60.9\%), pendidikan terakhir lebih dominan pada SMA/SMK yang berjumlah 28 responden (40.6\%), lama bekerja dominan pada 3-4 tahun yang berjumlah 25 responden $(36.2 \%)$, divisi penjualan paling dominan dengan jumlah 18 responden $(26.1 \%)$.

Hasil pengujian dari path coefficient variabel kompensasi (X1) mendapatkan nilai 0.522 dan Tstatistic mendapatkan nilai sebesar 5.532 (>1.96). Dapat dibuat kesimpulan bahwa H1 tidak ditolak, dan membuktikan bahwa kompensasi memiliki pengaruh yang positif dan signifikan terhadap kepuasan kerja karyawan.

Hasil pengujian dari path coefficient variabel lingkungan kerja (X2) mendapatkan nilai 0.366 dan t-statistic mendapatkan nilai sebesar 3.297 (>1.96). Dapat dibuat kesimpulan bahwa H2 tidak ditolak, dan membuktikan bahwa lingkungan kerja memiliki pengaruh yang positif dan signifikan terhadap kepuasan kerja karyawan.

\section{KESIMPULAN DAN SARAN}

Hasil dari penelitian ini menyatakan kepuasan kerja dipengaruhi oleh kompensasi dan lingkungan kerja. Kepuasan kerja disebabkan oleh dua faktor yaitu peristiwa dan agen. Peristiwa terdiri dari, antara lain, tantangan, kebutuhan fisik serta minat atas pekerjaannya; imbalan; dan 
kondisi fisik serta pencapaian tujuan. Agen terdiri dari, antara lain, karyawan yang bersangkutan; atasan, rekan kerja dan bawahan; perusahaan dan manajemen; dan tunjangan. Sampel yang diambil untuk penelitian ini adalah karyawan PT. Auto Prima Jaya sebanyak 69 responden, dengan kriteria antara lain, karyawan tetap yang minimal telah bekerja selama satu tahun dengan pendidikan terakhir SMA. Hasil pengujian hipotesis yang dilakukan, membuktikan kompensasi dan lingkungan kerja berpengaruh positif dan signifikan terhadap kepuasan kerja karyawan PT. Auto Prima Jaya.

\section{REFERENSI}

Al-Omari, K., dan Okasheh, H. (2017). The influence of work environment on job performance: A case study of engineering company in Jordan. International Journal of Applied Engineering Research, 12(24), 15544-15550.

Bailey, A. A., Albassami, F., Al-Meshal, S. (2016), The roles of employee job satisfaction and organizational commitment in the internal marketing-employee bank identification relationship. International Journal of Bank Marketing, 34(6), 821-840

Dessler, G. (2017). Human Resource Management. United Kingdom: Pearson.

Hasibuan, H. M. S. (2012). Manajemen Sumber Daya Manusia (Edisi Revisi, Cetakan Ke Tigabelas). Jakarta: Bumi Aksara.

Kinicki, A. dan Fugate, M. (2018). Organizational Behavior: A Practical, Problem-Solving Approach. (2nd Edition). NY: McGraw-Hill

Kreitner, R., dan Kinicki, A. (2014). Perilaku Organisasi: organizational behavior. (Edisi ke9). Jakarta Selatan: Salemba Empat.

Landy, F.J. dan Conte, J.M. (2013). Work in the $21^{\text {st }}$ Century: An Introduction to Industrial and Organizational Psychology (4th Edition). USA: John Wiley dan Sons, Inc.

Milkovich G.T., Newman, .M., dan Gerhart, B. (2011). Compensation (10th Edition). Singapore: McGraw-Hill

Mondy, R. W., dan Martocchio, J. J. (2016). Human Resource Management (14th Edition). United Kingdom: Pearson Education Inc.

Noe, R. A., Hollenbeck, J. R., Gerhart, B., Wright, P. M. (2010). Human Resource Management: Gaining a Competitive Advantage, (7th Edition). New York: McGraw-Hill.

Pawirosumarto, S., Sarjana, P. K., dan Gunawan, R. (2017). The effect of work environment, leadership style, and organizational culture towards job satisfaction and its implication towards employee performance in Parador Hotels and Resorts, Indonesia. International Journal of Law and Management.

Robbins, S. P., DeCenzo, D. A., dan Coulter, M. (2013). Fundamentals of Management: Essential Concepts and Applications (8th Edition). Upper Saddle River, N.J: Prentice Hall.

Robbins, S. P., Judge, T. A., dan Breward, K.,E. (2016). Essentials of Organizational Behaviour (1st Canadian Edition). Pearson Education Canada.

Sedarmayanti. (2009). Tata Kerja dan Produktivitas Kerja. Bandung: Mandar Maju.

Sedarmayanti. (2016). Manajemen Sumber Daya Manusia: Reformasi Birokrasi dan Manajemen Pegawai Negeri Sipil. Bandung: Refika Aditama.

Sekaran, U., dan Bougie, R. (2016). Research Methods for Business: A Skill Building Approach (7th Edition). United Kingdom: John Wiley dan Sons Ltd

Zhang, M. (2015). The Analysis of Organizational Work Environment Factors Affecting Training Transfer: A Questionnaire Survey in Chinese Enterprises. Doctoral dissertation. University Institute of Lisbon. 